\title{
THE EFFECT OF VARIABLE DELAYS ON SELF-CONTROL
}

\author{
John J. Chelonis, George King, \\ A. W. LOgue, AND Henry TOBIN \\ STATE UNIVERSITY OF NEW YORK AT STONY BROOK AND \\ DUKE UNIVERSITY MEDICAL CENTER
}

\begin{abstract}
Five pigeons served as subjects in an experiment that examined the effects of variable as opposed to fixed delays on preference in a self-control paradigm (choice between larger, more delayed and smaller, less delayed reinforcers). Nonindependent concurrent variable-interval schedules were used to measure choice. When delays to the larger, more delayed reinforcers were variable as opposed to fixed, the subjects showed an increased preference for that alternative (the self-control alternative). A series of regressions revealed that the hyperbolic decay model and incentive theory provided poor fits to the data, but a modified version of the generalized matching law provided an adequate fit. Together, consistent with a general prediction made by discounting models, the data supported the conclusion that variable delays can increase self-control. However, specific discounting models were not able to explain the present data well.

Key words: choice, self-control, reinforcement delay, concurrent schedules of reinforcement, generalized matching law, hyperbolic decay model, incentive theory, key peck, pigeons
\end{abstract}

Self-control has been defined as the choice of a larger, more delayed reinforcer over a smaller, less delayed reinforcer, and impulsiveness as the opposite (Ainslie, 1974; Grosch \& Neuringer, 1981; Logue, 1988; Rachlin \& Green, 1972). In the laboratory, using food as the reinforcer, pigeons are generally impulsive even when the only way to maintain their body weights is to choose the self-control alternative (Logue, Chavarro, Rachlin, \& Reeder, 1988).

One novel way to increase pigeons' self-control might be to use a variable delay rather than a fixed delay for the self-control alternative. Previous research has shown that pigeons and rats choose an alternative with a variable delay over an alternative with an equivalent fixed delay with the same arithmetic mean (e.g., Cicerone, 1976; Mazur, 1984; Pubols, 1962; Rider, 1983). Humans also tend to choose variable delays (but only when there are no available signals to segment the phases

Some of the data reported in this paper were presented at the annual meeting of the Association for Behavior Analysis in San Francisco, May 1992. This research was supported by a grant from the National Science Foundation. We thank R. Reeder, G. Higgins, and R. Chorley for their maintenance of the computers and the apparatus; W. Morrison, V. Palamand, E. Seigel, and D. Cross for assistance in analysis of results; and $\mathrm{H}$. Rachlin for comments on previous versions of the manuscript. Correspondence and requests for reprints should be addressed to $A$. W. Logue, Department of Psychology, State University of New York at Stony Brook, Stony Brook, New York 11794-2500 (E-mail: ALOGUE@SBCCMAIL). of the procedure; Kohn, Kohn, \& Staddon, 1992).

Discounting models can describe and predict the preference for a variable delay over a fixed delay. These models assume that the value of an item decreases as the delay to the receipt of that item is increased. More specifically, these models postulate that the value of a given reinforcer decreases in a nonlinear fashion as the delay to the reinforcer increases (Kagel, Green, \& Caraco, 1986). The graph of this function is shaped such that increasing the delay from $t$ to $t+x$ units decreases the value of a reinforcer less than decreasing the delay from $t$ to $t-x$ units increases the value of a reinforcer (Zabludoff, Wecker, \& Caraco, 1988). Therefore, when there are two reinforcers, one with a delay of $t-x$ and the other with a delay of $t+x$, the mean of their values, $v^{\prime}$, will be greater than $v$, the value for a reinforcer of delay $t$. Further, the difference between $v$ and $v^{\prime}$ will increase as the value of $x$ is increased. For example, assume a subject is choosing between a fixed delay of $10 \mathrm{~s}$ and a variable delay with two possible values for the delay that are equally likely to occur (such as $5 \mathrm{~s}$ and $15 \mathrm{~s}$ ). Thus, $t$ for the fixed delay is 10 $\mathrm{s}$, and $t+x$ and $t-x$ for the variable delay are $15 \mathrm{~s}$ and $5 \mathrm{~s}$, respectively. Although the mean delays are equal for both alternatives $(10 \mathrm{~s})$, the value of the reinforcer for the variable alternative $\left(v^{\prime}\right)$ is greater than the value of the reinforcer for the fixed delay $(v)$. This 
is because the increase in value of the reinforcer when it is delayed $5 \mathrm{~s}$ instead of $10 \mathrm{~s}$ is greater than the decrease in the value of the reinforcer when it is delayed $15 \mathrm{~s}$ instead of $10 \mathrm{~s}$.

One discounting model that can be used to describe the effects of variable delays on preference is the hyperbolic decay model (Mazur, 1984). This model weights shorter delays more heavily than larger delays in determining the value of a single reinforcer outcome. In addition, according to this model, the value of a given outcome is positively related to the amount of the reinforcer and is negatively related to the delay of that reinforcer. When there are two outcomes differing in reinforcer amount and the delay to one of these outcomes varies, Mazur's hyperbolic decay model predicts choices between two outcomes as follows:

$$
\frac{B_{\mathrm{L}}}{B_{\mathrm{R}}}=b\left(\frac{\sum_{j=1}^{n} P_{j}\left(\frac{A_{\mathrm{L}}}{1+k D_{j \mathrm{~L}}}\right)}{\left(\frac{A_{\mathrm{R}}}{1+k D_{\mathrm{R}}}\right)}\right),
$$

in which $B_{\mathrm{L}}$ and $B_{\mathrm{R}}$ are the number of choices of the two outcomes (e.g., left and right key pecks), $n$ is the number of differing delays that follow a left choice response, $P_{j}$ is the probability of the occurrence of each of the left delays, $A_{\mathrm{L}}$ and $A_{\mathrm{R}}$ are the amounts of the left and right reinforcers that the subject receives, $D_{j \mathrm{~L}}$ and $D_{\mathrm{R}}$ are the left and right delays between the choice period and reinforcer access, $k$ is a constant, and $b$ is a parameter that helps to describe bias for a particular response alternative that is consistent across experimental conditions (see Baum, 1974).

Mazur's hyperbolic decay model has provided an excellent fit to data obtained when subjects chose between an adjusting delay and a set of variable delays (with the same reinforcer amounts for both alternatives; Mazur, 1984), or between a fixed and an adjusting delay (with unequal reinforcer amounts for the two alternatives; Mazur, 1987). By adjusting the value of $k$ to reflect the time spent in the initial link, this model has also been extended to predict preferences for variable delays over fixed delays using a concurrent-chains procedure with terminal links of constant duration (Davison, 1988).

A second discounting model that attempts to describe preference for variable delays is Killeen's incentive theory (Killeen, 1982; Killeen \& Fantino, 1990). This model has been successfully used to describe preference for variable schedules in a concurrent-chains procedure by incorporating into the model a term similar to one used in delay-reduction theory, a term that describes the effects of the total amount of time spent in the initial link of a concurrent-chains procedure (Killeen \& Fantino, 1990). (Note, however, that by itself, delay-reduction theory predicts that subjects should show no preference between variable and fixed delays; see Fantino, 1977.)

Killeen's (1982) incentive theory can be modified to predict behavior in a self-control paradigm as follows (as interpreted by Fantino \& Davison, 1983; see also Logue \& Chavarro, 1987):

$$
\frac{B_{\mathrm{L}}}{B_{\mathrm{R}}}=b\left(\frac{r_{\mathrm{L}}\left[\exp ^{\left(-q / A_{\mathrm{L}}\right) D_{\mathrm{L}}}+1 / D_{\mathrm{L}}\right]}{r_{\mathrm{R}}\left[\exp ^{\left(-q / A_{\mathrm{R}}\right) D_{\mathrm{R}}}+1 / D_{\mathrm{R}}\right]}\right),
$$

in which $B_{i}, A_{i}, D_{i}$, and $b$ are defined as for Equation $1 ; r_{L}$ and $r_{R}$ are the overall rates of reinforcement for the left and right alternatives [1/(programmed choice time plus average reinforcer delay time), separately for each alternative; see Squires \& Fantino, 1971]; and $q$ is the probability that some other extraneous response will become conditioned during the delay period. In Equation 2, the part of the numerator that is in brackets expresses the combined directive effects of the left reinforcer alternative, and the part of the denominator that is in brackets expresses the combined directive effects of the right reinforcer alternative. According to Killeen (1982), the combined directive effects of a schedule are the changes in a given response due to primary and conditioned reinforcement of that response.

Expressed as Equation 2, incentive theory is not designed to predict behavior for conditions that compare preferences between variable and fixed delays. However, Killeen (1982) suggested a way to modify Equation 2 to describe a reinforcer alternative with variable delays. According to Killeen, assuming that each of the delay variations occurs with equal frequency, the combined directive effects of a variable schedule can be estimated by computing the combined directive effects for the variable-delay alternative separately for each 
delay value. Then a mean of these effects is taken, and that mean is used in Equation 2 as the value of combined directive effects for the variable-delay alternative.

A third discounting model that describes preference for variable delays is the generalized matching law (Baum, 1974), modified for self-control paradigms in which reinforcer delay varies (see Grace, 1993; Logue, Rodriguez, Peña-Correal, \& Mauro, 1984). According to this model, preference can be described as

$$
\frac{B_{\mathrm{L}}}{B_{\mathrm{R}}}=b\left(\frac{A_{\mathrm{L}}}{A_{\mathrm{R}}}\right)^{s_{A}}\left(\frac{\mu_{\mathrm{R}}}{\mu_{\mathrm{L}}}\right)^{a_{1}}\left(\frac{\sigma_{\mathrm{L}}+1}{\sigma_{\mathrm{R}}+1}\right)^{a_{2}},
$$

in which $B_{\mathrm{L}}$ and $B_{\mathrm{R}}$ represent the number of choices of the left and right response alternatives; $A_{\mathrm{L}}$ and $A_{\mathrm{R}}$ represent the amounts of the reinforcers received for responses on those alternatives; $\mu_{\mathrm{L}}$ and $\mu_{\mathrm{R}}$ represent the mean delays to those reinforcers (the times between choice and reinforcer delivery); $\sigma_{\mathrm{L}}$ and $\sigma_{\mathrm{R}}$ represent the standard deviations of the delays to reinforcement for the left and right alternatives; the variables $s_{A}, a_{1}$, and $a_{2}$ represent the subject's sensitivity to variation in amount, mean delay, and standard deviation of delay, respectively; and $b$ is a measure of response bias.

Equation 3 has provided a good fit to concurrent-chains data in which subjects chose between variable-interval and fixed-interval schedules during the terminal links (Grace, 1993; Killeen, 1968), and has also been able to account for the intransitivities in choice between fixed and variable schedules that were found by Navarick and Fantino (1972; Grace, 1993). In addition, the generalized matching law, which is similar in many respects to Equation 3, has been quite successful in describing data from self-control paradigms in which reinforcer delay did not vary (Chavarro \& Logue, 1988; Logue, 1988; Logue et al., 1984).

The present research had three purposes. First, it investigated the effect of variable delays on self-control, an effect that has never before been examined. In fact, the present research is the first to examine the effect of variable delays on preference when reinforcer amounts are unequal. In the present experiment, different sets of variable delays to the larger reinforcer were used to determine the function relating these sets and self-control. All of the above models predict that subjects should exhibit an increase in self-control as the variability of the delay to the larger reinforcer increases. Should delay variability increase selfcontrol, this would be one of the very few manipulations that increases self-control in the subjects used in this experiment (i.e., pigeons; see Logue, 1988).

Second, the present experiment attempted to determine whether different absolute values for fixed delays would have different effects on self-control if the ratio of the delays remained the same. The version of the generalized matching law that was modified to account for variable reinforcer delays (Equation 3 ) does not predict any difference in choice when different absolute values for fixed delays are used as long as the ratio of the mean delays and the standard deviation of the delays remain the same. However, both the hyperbolic decay model (Equation 1) and incentive theory (Equation 2) predict that as the absolute values for the delays increase while the ratio of the delays is held constant, preference for the alternative with the shorter absolute delay will increase. In addition, most previous research has found that preference for the alternative with the shorter delay does indeed increase as the absolute values of the delays increase, even when the ratio of the delays remains constant (Green \& Snyderman, 1980; Logue \& Chavarro, 1987; Williams \& Fantino, 1978). However, increased preference for the alternative with the longer delay has also been shown to occur (Green \& Snyderman, 1980).

Finally, the present experiment attempted to determine whether increasing the number of delays presented by the variable alternative while the mean delay remained constant (thus decreasing delay variability) would decrease preference for that alternative. All of the above models predict that if a third value is added to an alternative with two values and the same mean, preference for that alternative should decrease because the probability of occurrence of the shorter delays has thereby decreased. Consistent with this prediction, Rider (1983) found that preference for variable delays increased as the probability of the occurrence of the shortest delay increased. However, as the probability of the occurrence of Rider's shortest delay increased, the mean delay of the variable alternative decreased as well, which could have accounted for the increase in preference 


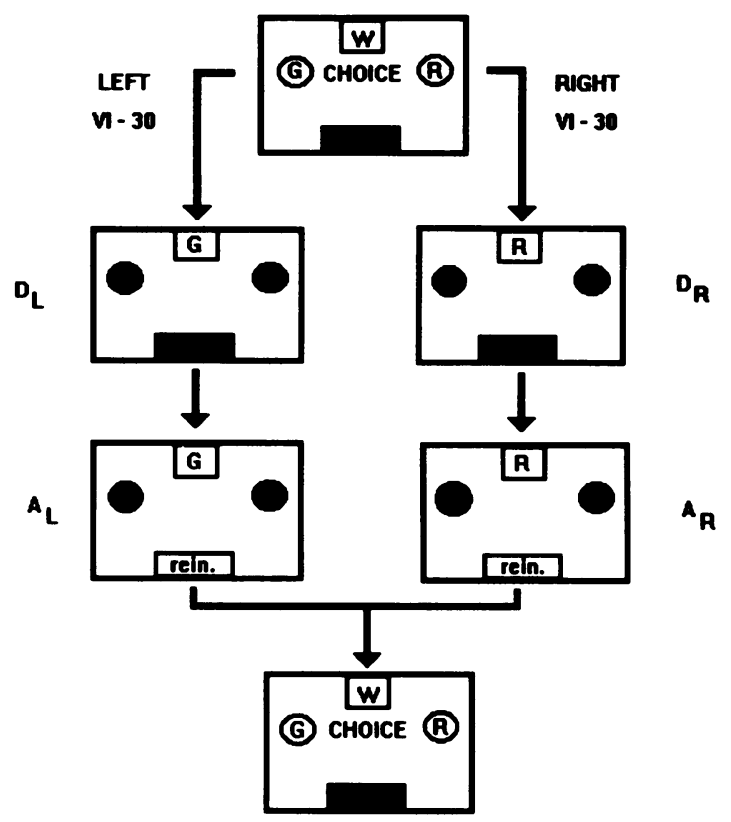

Fig. 1. Diagram of the procedure for one reinforcement cycle. The boxes containing $\mathrm{W}, \mathrm{G}$, and $\mathrm{R}$ correspond to the white, red, and green houselights, respectively. The circles containing $\mathrm{G}$ and $\mathrm{R}$ correspond to the green and red keylights, respectively. $D_{\mathrm{L}}, D_{\mathrm{R}}, A_{\mathrm{L}}$, and $A_{\mathrm{R}}$ correspond to the left and right reinforcer delays and reinforcer amounts, respectively.

for the variable alternative. Therefore, the effects on preference of the number of variable delays are as yet unclear.

\section{METHOD}

\section{Subjects}

The subjects were five experimentally naive White Carneau pigeons. They were maintained at $80 \%$ of their free-feeding weights using supplemental feedings following the experimental sessions.

\section{Apparatus}

The experiment was conducted in an experimental chamber that was $32 \mathrm{~cm}$ long, 32 $\mathrm{cm}$ wide, and $30 \mathrm{~cm}$ high. Two response keys, each $1.9 \mathrm{~cm}$ in diameter, were mounted on the front wall, $21 \mathrm{~cm}$ above the floor of the chamber and $12.5 \mathrm{~cm}$ apart. These keys required a minimum force of $0.17 \mathrm{~N}$ to operate. The left key could be transilluminated with green light, and the right key with red light. An opening to a food hopper, $5 \mathrm{~cm}$ in diameter and $9.5 \mathrm{~cm}$ below the two keys and centered between them, allowed the pigeons access to mixed grain. On the outside and on top of the chamber were two 7.5-W white lights, one 7.5-W red light, and one $7.5-\mathrm{W}$ green light. A Plexiglas-covered hole in the aluminum ceiling allowed the light from these bulbs to illuminate the chamber. The chamber was enclosed in a soundattenuating box that contained an air blower for ventilation. An IBM-XT ${ }^{\circledR}$ computer, located in another room, using a program written in CONMAN, controlled the stimuli and recorded the responses.

\section{Procedure}

Figure 1 shows the procedure for one reinforcement cycle (for similar self-control paradigms see, e.g., Chavarro \& Logue, 1988; King \& Logue, 1990; Logue \& Chavarro, 1987; Logue et al., 1984). At the beginning of a session, the experimental chamber was illuminated by the white houselight, the left key was transilluminated green, and the right key was transilluminated red. An effective left key peck initiated a delay period (time between a choice and reinforcer access), turned off both keylights and the white houselight, and turned on the green overhead light. At the end of the delay period, grain was made available. Following access to grain, the colored overhead lights were turned off and the white overhead light and the keylights were again lit. If a pigeon chose the right key, the sequence of events was similar except that the red overhead light was illuminated instead of the green overhead light, and the pigeon received access to grain. A peck on a lit key was followed by a feedback click, but pecks on darkened keys had no effect. Sessions were terminated after 30 reinforcers had been received.

A Stubbs and Pliskoff (1969) nonindependent concurrent variable-interval (VI) 30-s VI 30 -s schedule, similar to that employed in much other self-control research, was used (Chavarro \& Logue, 1988; King \& Logue, 1990; Logue \& Chavarro, 1987). Scheduling concurrent VIs nonindependently insures that subjects are exposed to the contingencies for both left and right key pecks, and that relative reinforcement rates for both keys remain equal and independent of preference for either alternative. Such a procedure is essential if preference is to be assessed independently of rel- 
Table 1

Condition parameters and mean choice ratios.

\begin{tabular}{|c|c|c|c|c|c|c|c|c|}
\hline \multirow[b]{2}{*}{$\begin{array}{l}\text { Condi- } \\
\text { tion }^{\mathrm{a}}\end{array}$} & \multicolumn{2}{|c|}{ Amount } & \multicolumn{3}{|c|}{ Left delay } & \multirow{2}{*}{$\begin{array}{c}\text { Right } \\
\text { delay } \\
\text { intervals }\end{array}$} & \multirow{2}{*}{$\begin{array}{c}\text { Choice } \\
\text { ratio } \\
\text { mean }(S E)^{\mathrm{b}}\end{array}$} & \multirow[b]{2}{*}{ Sessions } \\
\hline & Left & Right & Intervals & Mean & $\begin{array}{l}\text { Standard } \\
\text { deviation }\end{array}$ & & & \\
\hline 1 & 4.5 & 4.5 & 1,9 & 5 & 4.0 & 5 & $2.1(0.4)$ & 41 \\
\hline $2(\mathrm{~L})$ & 6 & 3 & 5,35 & 20 & 15.0 & 10 & $3.0(0.5)$ & 39 \\
\hline $3(\mathrm{~L})$ & 6 & 3 & 20 & 20 & 0.0 & 10 & $1.3(0.2)$ & 39 \\
\hline $4(S)$ & 6 & 3 & 1,19 & 10 & 9.0 & 5 & $2.4(0.2)$ & 23 \\
\hline $5(S)$ & 6 & 3 & 10 & 10 & 0.0 & 5 & $0.5(0.1)$ & 39 \\
\hline $6(\mathrm{~L})$ & 6 & 3 & 19,21 & 20 & 1.0 & 10 & $0.7(0.2)$ & 36 \\
\hline 7 & 6 & 3 & $1,10,19$ & 10 & 7.3 & 5 & $1.6(0.3)$ & 25 \\
\hline $8(\mathrm{~L})$ & 6 & 3 & 1,39 & 20 & 19.0 & 10 & $3.1(0.6)$ & 23 \\
\hline $9(\mathrm{~S})$ & 6 & 3 & 9,11 & 10 & 1.0 & 5 & $1.7(0.4)$ & 20 \\
\hline $10(S)$ & 6 & 3 & 5,15 & 10 & 5.0 & 5 & $1.7(0.4)$ & 27 \\
\hline 11 & 6 & 3 & $1,20,39$ & 20 & 15.5 & 10 & $3.7(0.6)$ & 56 \\
\hline $12(\mathrm{~L})$ & 6 & 3 & 11,29 & 20 & 9.0 & 10 & $2.8(0.8)$ & 24 \\
\hline $13(\mathrm{~L})$ & 6 & 3 & 15,25 & 20 & 5.0 & 10 & $2.3(0.7)$ & 46 \\
\hline 14 & 3 & 6 & 5 & 5 & 0.0 & 1,19 & $1.7(0.3)$ & 40 \\
\hline
\end{tabular}

Note. All amount and delay values are given in seconds.

${ }^{a} \mathrm{~L}$ and $\mathrm{S}$ indicate short and long conditions, respectively (see text).

b $N$ equal to the 5 subjects.

ative reinforcement rate, as was the case here. Specifically, in the concurrent experiment, the reinforcers were delivered using a single VI 15 -s schedule constructed according to the progression suggested by Fleshler and Hoffman (1962). When an interval in this VI schedule had timed out, a reinforcer was randomly assigned to either the left or right key (with the constraints that the pigeon could not receive more than six reinforcers in a row on a given alternative and that, in each session, half of the reinforcers had to be assigned to each response alternative). The VI schedule then ceased timing until after a response had occurred on the appropriate key and the reinforcer had been received.

A 3-s changeover delay (COD) was also in effect. A pigeon could not receive a reinforcer for a peck on a given key until at least $3 \mathrm{~s} \mathrm{had}$ elapsed since a previous peck on that key with no intervening pecks on the other key. The purpose of the COD was to decrease the probability of reinforcement of sequences of responses involving both keys.

The experiment consisted of 14 conditions in the order shown in Table 1. Some conditions in this table are designated as short conditions and others as long conditions. Short conditions are those in which the delay to the smaller amount was fixed at $5 \mathrm{~s}$ and the delay to the larger amount was either fixed at $10 \mathrm{~s}$ or con- sisted of two values with a mean of $10 \mathrm{~s}$. Long conditions are those in which the delay to the smaller amount was fixed at $10 \mathrm{~s}$ and the delay to the larger amount was either fixed at $20 \mathrm{~s}$ or consisted of two values with a mean of 20 s. Thus the short and the long conditions provided two sets of conditions with which to examine the effects of the size of the components of the delay on self-control. There were four additional conditions in the experiment. Condition 1 was included to examine the effects on preference of delay variability when both reinforcer amounts were equal, and Condition 14 was included so that it could be compared with Condition 4 to test for response bias. Conditions 7 and 11 were included so that they could be compared with Conditions 4 and 8 , respectively, to examine whether preference is affected by having three rather than two delays for the variable alternative.

Conditions were changed for all of the pigeons simultaneously, when all of the pigeons had met certain stability criteria. These criteria specified that, first, all pigeons had to experience a minimum of 10 sessions on a given condition. Second, for the last five consecutive sessions of a condition for each pigeon, the ratio of the number of left responses divided by the number of right responses (i.e., the choice ratio) had to be neither higher nor lower than any of the ratios for that pigeon in previous 
sessions of that condition. In other words, pigeons were exposed to a given condition until, for all of the pigeons simultaneously, each pigeon's five most recent consecutive choice ratios were within the range of the previous choice ratios emitted by that pigeon on that condition. Table 1 shows the number of sessions that the pigeons were exposed to each condition.

\section{RESULTS}

The mean ratio of left responses divided by the number of right responses over the last five (stable) sessions of each condition was used as the measure of choice for each pigeon in Conditions 1 through 13 (right divided by left responses for Condition 14). Thus, the choice ratios measured self-control for Conditions 2 through 14. (The Appendix shows the means and standard errors of left and right responses over the last five sessions, separately for each subject and each condition.)

Table 1 shows the mean choice ratios and their standard errors for each condition over all 5 subjects in that condition. Analysis of variance indicates that the choice ratios did vary as a function of delay variability for the short conditions, $F(3,12)=18.59, p<.001$, and the long conditions, $F(5,20)=5.89, p<$ .01 . Table 1 also indicates that, in Condition 1 , in which the amount of access to grain was fixed at $4.5 \mathrm{~s}$ for both alternatives and the mean delay was $5 \mathrm{~s}$ for both alternatives, the pigeons made about twice as many left as right responses, statistically significantly more than a ratio of $1.0, t(4)=3.09, p<.05$. In other words, the pigeons showed a significant preference for a variable delay over a fixed delay when both reinforcer amounts and the arithmetic means of both reinforcer delays were equal.

The choice ratios for Conditions 4 and 14 were compared to determine whether or not the pigeons had a position or color bias. The reinforcer parameters for these conditions were identical except that the contingencies for left and right key pecks were reversed. There was no statistically significant position or color bias for the group, $t(4)=2.01, p>.05$. However, 4 of the 5 subjects showed greater preference for the larger, more delayed reinforcer in Condition 4 than in Condition 14, and only 1 subject showed the reverse. Therefore, in fitting the models to the data as described below, bias was allowed to vary for each individual subject to determine the best fit.

In order to determine the ability of each model to describe the choice ratios as a function of delay variability, nonlinear regression was performed. This was done by performing a series of regressions using the means of the subjects' obtained choice ratios for each condition and the predicted choice ratios for each condition. The regressions were performed using a program that was written in QUICKBASIC. To perform these regressions, each model's free parameters were allowed to vary between 0.1 and 4 with a step size of 0.1 , with the exception of $q$ in incentive theory (which was allowed to vary between .01 and 1.00 with a step size of .01). All of these values were chosen so as to encompass broadly all of the values that have been obtained for these free parameters in previous research (Davison, 1988; Grace, 1993; Killeen, 1982; Mazur, 1984). In using these possible free parameters to perform the regressions separately for each model and each condition, the predicted choice ratio was calculated for each subject using each possible combination of free parameters. Next, values of $R^{2}$ were computed by regressing the choice ratios predicted for the different conditions by a particular set of free parameters against the actual choice ratios obtained for each subject. Then the $R^{2}$ values were compared for each combination of free parameters to find the set of free parameters that yielded the largest value of $R^{2}$ for each subject. Separate regressions were conducted for the short conditions and the long conditions (thus, data from Conditions 1, 7, 11, and 14 were not used for these regressions). Because the present experiment did not vary reinforcer amounts or mean delays within a group of conditions being analyzed, to obtain the predicted choice ratios for the modified version of the generalized matching law, Equation 3 was reduced to

$$
\frac{B_{\mathrm{L}}}{B_{\mathrm{R}}}=c\left(\frac{\sigma_{\mathrm{L}}+1}{\sigma_{\mathrm{R}}+1}\right)^{a_{2}},
$$

in which $c$ is a combination of the free parameter $b$, the ratio of the amounts raised to the $s_{A}$ power, and the ratio of the mean delays raised to the $a_{1}$ power. Tables 2,3 , and 4 show the results of the regressions for the hyperbolic decay model (Equation 1), Killeen's incentive theory (Equation 2), and the modified version of the generalized matching law (Equation 4). 
Table 2

Summary of regressions for hyperbolic decay model (Equation 1).

\begin{tabular}{|c|c|c|c|c|c|c|}
\hline \multirow{2}{*}{$\begin{array}{c}\text { Sub- } \\
\text { ject }\end{array}$} & \multicolumn{3}{|c|}{ Short conditions } & \multicolumn{3}{|c|}{ Long conditions } \\
\hline & $b$ & $k$ & $R^{2}$ & $b$ & $k$ & $R^{2}$ \\
\hline 1 & 0.5 & 1.8 & .89 & 0.8 & 0.2 & .40 \\
\hline 2 & 1.6 & 0.2 & .18 & 2.0 & 0.1 & .19 \\
\hline 3 & 0.9 & 0.6 & .72 & 1.1 & 0.1 & .17 \\
\hline 4 & 0.9 & 0.3 & .76 & 1.7 & 0.1 & .30 \\
\hline 5 & 1.2 & 0.3 & .38 & 1.2 & 0.2 & .78 \\
\hline
\end{tabular}

Figure 2 plots the mean choice ratios for each condition as well as the best fitting functions for these results, separately for the short and long conditions. This figure provides a visual comparison of the predictions of all three models using one possible measure of delay variability: standard deviation (see also Table 1). Standard deviation was chosen instead of another measure of variability because Equation 4 specifically uses standard deviation. It is apparent that the data in Figure 2 follow negatively accelerating functions. However, the graphs of the best fitting functions for both the hyperbolic decay model and incentive theory are positively accelerating. Therefore, these functions clearly do not fit the data. In contrast, the graph of the modified version of the generalized matching law (Equation 4) is negatively accelerating and does appear to fit the data. More detailed examination of the predictions of this model showed no statistically significant differences between the values of $b$ and $a_{2}$ for the short and long conditions, $t(4)$ $=-0.8, p>.05$; and $t(4)=1.0, p>.05$; respectively. Figure 3 shows individual subjects' predicted and obtained choice ratios for Equation 4.

Nevertheless, although the overall shape of the function predicted by Equation 4 is negatively accelerating, as are the data, and al-

Table 3

Summary of regressions for incentive theory (Equation 2).

\begin{tabular}{cccccccc}
\hline \multirow{2}{*}{$\begin{array}{c}\text { Sub- } \\
\text { ject }\end{array}$} & \multicolumn{3}{c}{ Short conditions } & & \multicolumn{3}{c}{ Long conditions } \\
\cline { 2 - 3 } \cline { 6 - 7 } & $q$ & $R^{2}$ & & $b$ & $q$ & $R^{2}$ \\
\hline \hline 1 & 0.9 & 1.0 & .88 & & 1.2 & .34 & .30 \\
2 & 2.7 & .01 & .11 & & 3.0 & .31 & .08 \\
3 & 1.5 & .67 & .72 & & 2.1 & .01 & .09 \\
4 & 1.5 & .42 & .76 & & 2.9 & .17 & .10 \\
5 & 1.9 & .41 & .37 & & 1.9 & .26 & .63 \\
\hline
\end{tabular}

\section{Table 4}

Summary of regressions for modified generalized matching law (Equation 4).

\begin{tabular}{|c|c|c|c|c|c|c|}
\hline \multirow{2}{*}{$\begin{array}{l}\text { Sub- } \\
\text { ject }\end{array}$} & \multicolumn{3}{|c|}{ Short conditions } & \multicolumn{3}{|c|}{ Long conditions } \\
\hline & $c$ & $a_{2}$ & $R^{2}$ & $c$ & $a_{2}$ & $R^{2}$ \\
\hline 1 & 0.2 & 1.0 & .94 & 0.2 & 0.8 & .75 \\
\hline 2 & 1.6 & 0.3 & .56 & 1.9 & 0.3 & .51 \\
\hline 3 & 0.7 & 0.5 & .70 & 1.1 & 0.3 & .53 \\
\hline 4 & 0.9 & 0.3 & .70 & 1.0 & 0.5 & .67 \\
\hline 5 & 1.1 & 0.4 & .55 & 0.8 & 0.4 & .68 \\
\hline
\end{tabular}

though the percentages of variance accounted for by Equation 4 are significantly different from 0 [see the values of $R^{2}$ in Table $4 ; t(4)$ $=9.86, p<.01$ for the short conditions; $t(4)$ $=10.83, p<.01$ for the long conditions], these percentages are not particularly high. The mean $R^{2}$ value for the individual subjects whose data are shown in Table 4 is .69 for the short conditions and .65 for the long conditions.

A $t$ test was conducted to confirm any difference in self-control between conditions that

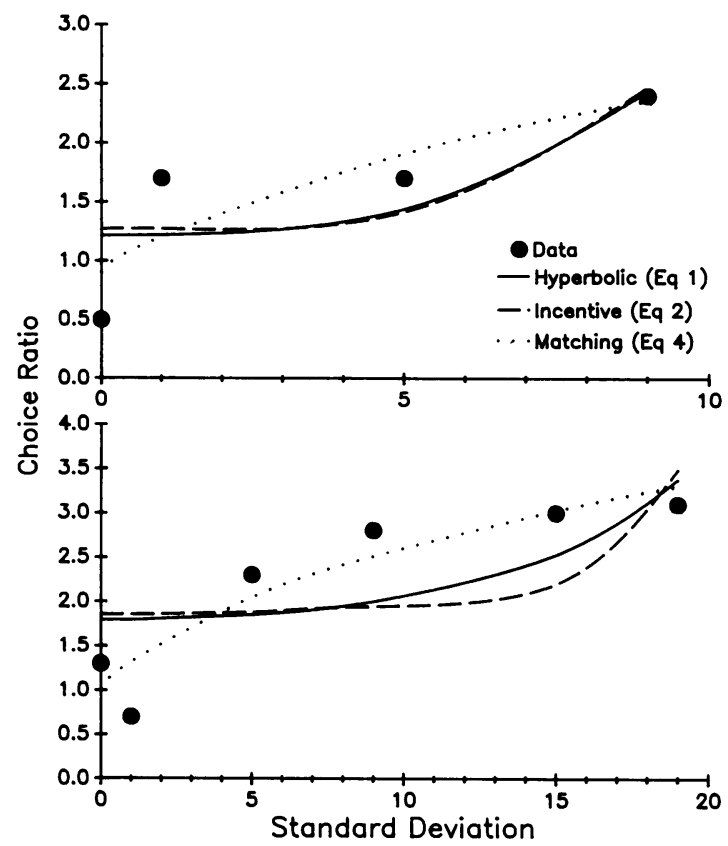

Fig. 2. Mean obtained self-control ratios and the selfcontrol ratios predicted by the hyperbolic decay model (Equation 1), incentive theory (Equation 2), and the modified version of the generalized matching law (Equation 4), all as a function of the standard deviation of the delay. The top panel shows data from the short conditions (mean delay on left $=10 \mathrm{~s}$ ), and the bottom panel shows data from the long conditions (mean delay on left $=20 \mathrm{~s}$ ). 


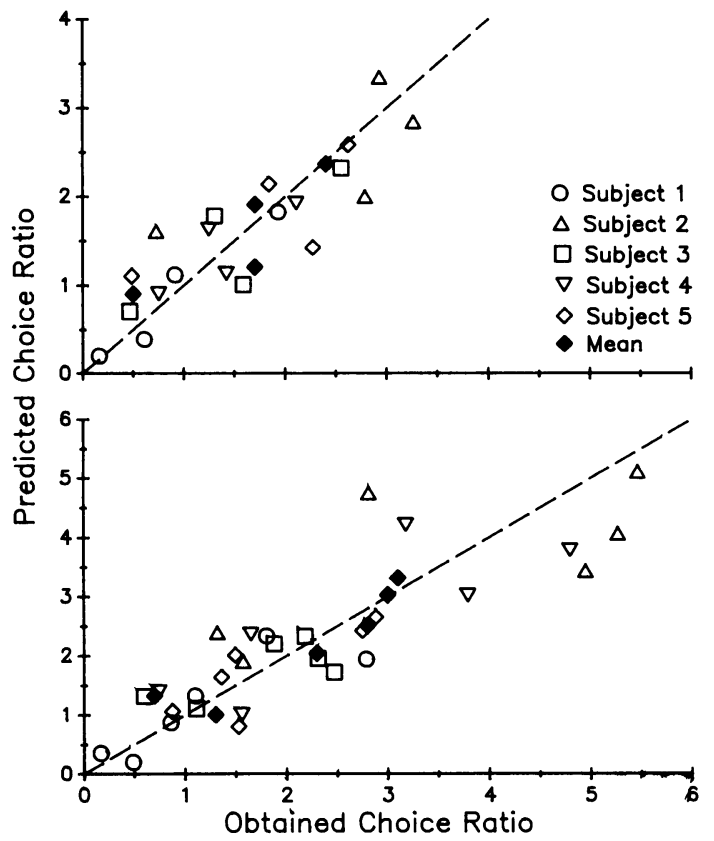

Fig. 3. Choice ratios predicted by the modified version of the generalized matching law (Equation 4) versus those actually obtained, shown separately for each subject. Subject means are also shown. The dashed line represents a perfect fit between the obtained and predicted choice ratios. The top panel shows data from the short conditions, and the bottom panel shows data from the long conditions.

had fixed delays and were identical in terms of their delay ratios, but were not identical in terms of their absolute (individual) delay values. Significantly more self-control responses were made when the delays were fixed at 20 $\mathrm{s}$ and $10 \mathrm{~s}$ (Condition 3) as opposed to $10 \mathrm{~s}$ and $5 \mathrm{~s}$ (Condition 5), $t(4)=6.1, p<.01$.

Finally, $t$ tests were conducted to confirm any difference in self-control between conditions that were identical in terms of their delay means and ranges, but were not identical in terms of the number of delays used. There was no statistically significant difference between the conditions in which the mean delay was $20 \mathrm{~s}$ and the range of the delays was $38 \mathrm{~s}$, but the number of delay values was either two or three (Conditions 8 and 11), $t(4)=-1.3, p$ $>.05$. In contrast, when the mean delay was $10 \mathrm{~s}$ and the range of the delays was $18 \mathrm{~s}$, the pigeons showed significantly more preference for the larger, more delayed reinforcer in the condition in which there were only two values for the delay than in the condition in which there were three values for the delay (Conditions 4 and 7 ), $t(4)=4.6, p<.01$.

\section{DISCUSSION}

The results for Condition 1 indicate that, consistent with previous research (Cicerone, 1976; Mazur, 1984; Pubols, 1962), the pigeons preferred an alternative with variable delays rather than fixed delays when the reinforcer amounts and the arithmetic means of the delays associated with each alternative were equal. Results from additional conditions indicated that using variable delays did have an effect on self-control responses: The degree of self-control tended to increase as delay variability increased (see Table 1). For example, as delay standard deviation increased, self-control increased in every condition except Condition 6 (see Figure 2).

The results from the present research agreed with a general prediction of discounting models: Preference for a variable delay increased as the delay variability increased. However, the hyperbolic decay model (Equation 1) and incentive theory (Equation 2) predicted that behavior ratios would increase in accordance with a positively accelerating function as delay variability increased. In fact, the ratios obtained increased in accordance with a negatively accelerating function, which is predicted by the modified version of the generalized matching law (Equation 4) when the parameter $a_{2}$ (sensitivity to the standard deviation of reinforcer delay) is less than 1.0 (see Table 4 and Figure 2). Further, although the data from the long and short conditions were fit separately, there were no significant differences between the values of the best fitting free parameters obtained for those two sets of conditions. Thus, subjects' response bias and sensitivity to standard deviation of delay, as measured by Equation 4, appear to have been similar in both sets of conditions.

One possible reason why a negatively accelerating function best fit the data could have been that nonindependent concurrent schedules were used to schedule reinforcers in the present experiment. This type of procedure could have caused subjects to exhibit less extreme preference than would have been obtained using independent concurrent schedules. In the limit, exclusive preference cannot be obtained with nonindependent concurrent schedules because subjects must respond on both alternatives to receive reinforcement.

However, there are two reasons why this explanation of the results is unlikely. First, the 
hyperbolic decay model (which predicts a positively accelerating function) has previously provided a good fit to data that were obtained using nonindependent concurrent schedules (Davison, 1988). Second, even given the lowest overall response rate shown by any pigeon in the present experiment, a very extreme preference ratio of 5.0 would still have resulted in twice as many responses on the nonpreferred alternative as were necessary to receive all of the reinforcers from that alternative (see the Appendix). Thus the fact that the present data followed a negatively accelerating rather than a positively accelerating function does not appear to have been due to the use of nonindependent concurrent schedules.

One possible reason why the data in the present experiment seemed to follow a negatively accelerating function, but data in previous experiments examining the hyperbolic decay model and incentive theory seemed to follow positively accelerating functions, is that reinforcer amounts were not equal for the two response alternatives in the present experiment. Previous research that has examined the effect of variable delays on choice has employed the same reinforcer amount for both alternatives (Davison, 1988; Davison \& Smith, 1986; Killeen, 1982; Killeen \& Fantino, 1990; Mazur, 1984, 1986). The hyperbolic decay model and incentive theory may not be able to describe preference when reinforcer amounts are unequal and reinforcer delays vary. However, the results of the present experiment are, of course, limited to the delay and amount values tested here.

The only function that fit the present data adequately was the modified version of the generalized matching law with sensitivity to the standard deviation of the delays $\left(a_{2}\right.$ in Equation 4) less than 1.0. This function fit the data well because, unlike the other functions, the parameters could be adjusted to obtain a negatively accelerating function. In the present research, each subject's data approximately followed a function of this shape (except for Subjects 3 and 4 for the short conditions).

The prediction made by the hyperbolic decay model and incentive theory, that preference is a function of absolute, and not just relative, reinforcer values, was also confirmed. This finding is contrary to a basic assumption of the generalized matching law (including Equation 3 ) that if the ratio of the delays is held constant, variation in the absolute values of the delay should have no effect on preference. However, although the absolute values of the delays affected preference, the effect was in the opposite direction from what is predicted by the above models and from the results that have been obtained by other researchers (Green \& Snyderman, 1980; Logue \& Chavarro, 1987; Williams \& Fantino, 1978). There were a great many procedural differences in all of these experiments, so it is extremely difficult to know what might have been responsible for their differing results.

Finally, the present experiment showed that there was not a statistically significant difference in preference between two conditions, both of which had mean delays of $20 \mathrm{~s}$ and delay ranges of $38 \mathrm{~s}$, but one condition had two delay values and the other had three. However, in accordance with the predictions of the hyperbolic decay model, incentive theory, and the modified version of the generalized matching law, when the mean delays were $10 \mathrm{~s}$ and the delay ranges were $18 \mathrm{~s}$, the condition with only two delay values resulted in significantly more self-control responses than did the condition with three delay values. The lack of a statistically significant difference between the two conditions in which the mean delay was $20 \mathrm{~s}$ could have been due to unusually large intersubject variability. The standard errors for both of these conditions were relatively large.

In summary, this is the first demonstration that self-control can be increased by using variable rather than fixed delays for the self-control alternative. Further, as delay variability increased, self-control increased. However, using multiple values for the delay may reduce the effectiveness of the variable delay in enhancing self-control. Although the data conformed to general predictions made by discounting models, only a modified version of the generalized matching law provided an adequate fit to the data.

\section{REFERENCES}

Ainslie, G. W. (1974). Impulse control in pigeons. Journal of the Experimental Analysis of Behavior, 21, 485489.

Baum, W. M. (1974). On two types of deviation from the matching law: Bias and undermatching. Journal of the Experimental Analysis of Behavior, 22, 231-242.

Chavarro, A., \& Logue, A. W. (1988). Sensitivity to amount and delay of reinforcement: Effects of different types of concurrent variable-interval schedules. The Psychological Record, 38, 421-435. 
Cicerone, R. A. (1976). Preference for mixed versus constant delay of reinforcement. Journal of the Experimental Analysis of Behavior, 25, 257-261.

Davison, M. (1988). Delay of reinforcers in a concurrent-chain schedule: An extension of the hyperbolicdecay model. Journal of the Experimental Analysis of Behavior, 50, 219-236.

Davison, M., \& Smith, C. (1986). Some aspects of preference between immediate and delayed periods of reinforcement. Journal of Experimental Psychology: Animal Behavior Processes, 12, 291-300.

Fantino, E. (1977). Conditioned reinforcement, choice, and information. In W. K. Honig \& J. E. R. Staddon (Eds.), Handbook of operant behavior (pp. 313-339). Englewood Cliffs, NJ.: Prentice-Hall.

Fantino, E., \& Davison, M. (1983). Choice: Some quantitative relations. Journal of the Experimental Analysis of Behavior, 40, 1-13.

Fleshler, M., \& Hoffman, H. S. (1962). A progression for generating variable interval schedules. Journal of the Experimental Analysis of Behavior, 5, 529-530.

Grace, R. C. (1993). Violations of transitivity: Implications for a theory of contextual choice. Journal of the Experimental Analysis of Behavior, 60, 185-201.

Green, L., \& Snyderman, M. (1980). Choice between rewards differing in amount and delay: Toward a choice model of self-control. Journal of the Experimental Analysis of Behavior, 34, 135-147.

Grosch, J., \& Neuringer, A. (1981). Self-control in pigeons under the Mischel paradigm. Journal of the Experimental Analysis of Behavior, 35, 3-21.

Kagel, J. H., Green, L., \& Caraco, T. (1986). When foragers discount the future: Constraint or adaptation. Animal Behaviour, 34, 271-283.

Killeen, P. (1968). On the measurement of reinforcement frequency in the study of preference. Journal of the Experimental Analysis of Behavior, 11, 263-269.

Killeen, P. R. (1982). Incentive theory II. Models for choice. Journal of the Experimental Analysis of Behavior, 38, 217-232.

Killeen, P. R., \& Fantino, E. (1990). Unification of models for choice between delayed reinforcers. Journal of the Experimental Analysis of Behavior, 53, 189-200.

King, G. R., \& Logue, A. W. (1990). Choice in a selfcontrol paradigm: Effects of reinforcer quality. Behavioural Processes, 22, 89-99.

Kohn, A., Kohn, W. K., \& Staddon, J. E. R. (1992). Preferences for constant duration delays and constant sized rewards in human subjects. Behavioural Processes, $26,125-142$.

Logue, A. W. (1988). Research on self-control: An integrating framework. Behavioral and Brain Sciences, 11, 665-709.

Logue, A. W., \& Chavarro, A. (1987). Effect on choice of absolute and relative values of reinforcer delay, amount, and frequency. Journal of Experimental Psychology: Animal Behavior Processes, 13, 280-291.

Logue, A. W., Chavarro, A., Rachlin, H., \& Reeder, R. W. (1988). Impulsiveness in pigeons living in the experimental chamber. Animal Learning \& Behavior, $16,31-39$

Logue, A. W., Rodriguez, M. L., Peña-Correal, T., \& Mauro, B. C. (1984). Choice in a self-control paradigm: Quantification of experience-based differences. Journal of the Experimental Analysis of Behavior, 41, 5367.

Mazur, J. E. (1984). Tests of an equivalence rule for fixed and variable reinforcer delays. Journal of Experimental Psychology: Animal Behavior Processes, 10, 426436.

Mazur, J. E. (1986). Fixed and variable ratios and delays: Further tests of an equivalence rule. Journal of Experimental Psychology: Animal Behavior Processes, 12, 116-124.

Mazur, J. E. (1987). An adjusting procedure for studying delayed reinforcement. In M. L. Commons, J. E. Mazur, J. A. Nevin, \& H. Rachlin (Eds.), Quantitative analyses of behavior: Vol. 5. The effect of delay and of intervening events on reinforcement value (pp. 55-73). Hillsdale, NJ: Erlbaum.

Navarick, D. J., \& Fantino, E. (1972). Transitivity as a property of choice. Journal of the Experimental Analysis of Behavior, 18, 389-401.

Pubols, B. H. (1962). Constant versus variable delay of reinforcement. Journal of Comparative and Physiological Psychology, 55, 52-56.

Rachlin, H., \& Green, L. (1972). Commitment, choice, and self-control. Journal of the Experimental Analysis of Behavior, 17, 15-22.

Rider, D. P. (1983). Preference for mixed versus constant delays of reinforcement: Effect of probability of the short, mixed delay. Journal of the Experimental Analysis of Behavior, 39, 257-266.

Squires, N., \& Fantino, E. (1971). A model for choice in concurrent and concurrent-chains schedules. Journal of the Experimental Analysis of Behavior, 15, 27-38.

Stubbs, D. A., \& Pliskoff, S. S. (1969). Concurrent responding with fixed relative rate of reinforcement. Journal of the Experimental Analysis of Behavior, 12, 887895.

Williams, B. A., \& Fantino, E. (1978). Effects on choice of reinforcement delay and conditioned reinforcement. Journal of the Experimental Analysis of Behavior, 29, 77 86.

Zabludoff, S. D., Wecker, J., \& Caraco, T. (1988). Foraging choice in laboratory rats: Constant vs variable delay. Behavioural Processes, 16, 95-110.

Received August 4, 1993 Final acceptance March 8, 1994 


\section{APPENDIX}

\begin{tabular}{|c|c|c|c|}
\hline \multirow[b]{2}{*}{$\begin{array}{l}\mathrm{Pi}- \\
\text { geon }\end{array}$} & \multirow[b]{2}{*}{ Condition $^{\mathrm{a}}$} & \multicolumn{2}{|c|}{ Responses } \\
\hline & & $\begin{array}{l}\text { Left mean } \\
\qquad(S E)\end{array}$ & $\begin{array}{l}\text { Right mean } \\
\quad(S E)\end{array}$ \\
\hline \multirow[t]{14}{*}{1} & 1 & $591(27)$ & $415(28)$ \\
\hline & $2(\mathrm{~L})$ & 727 (147) & $261(62)$ \\
\hline & $3(\mathrm{~L})$ & $307(28)$ & $621(20)$ \\
\hline & $4(S)$ & $749(42)$ & $387(15)$ \\
\hline & $5(\mathrm{~S})$ & $183(12)$ & $1107(54)$ \\
\hline & $6(\mathrm{~L})$ & 145 (19) & $841(31)$ \\
\hline & 7 & $563(42)$ & 569 (13) \\
\hline & $8(L)$ & $678(88)$ & $423(30)$ \\
\hline & $9(\mathrm{~S})$ & $381(14)$ & $645(16)$ \\
\hline & $10(S)$ & $436(21)$ & $477(19)$ \\
\hline & 11 & $881(65)$ & $269(27)$ \\
\hline & $12(\mathrm{~L})$ & 589 (37) & $533(22)$ \\
\hline & $13(\mathrm{~L})$ & $419(27)$ & $489(35)$ \\
\hline & 14 & $158(7)$ & $392(9)$ \\
\hline \multirow[t]{14}{*}{2} & 1 & $591(31)$ & $330(37)$ \\
\hline & $2(\mathrm{~L})$ & $613(76)$ & 220 (29) \\
\hline & $3(\mathrm{~L})$ & $544(24)$ & 347 (17) \\
\hline & $4(S)$ & $742(17)$ & $254(6)$ \\
\hline & $5(S)$ & $422(25)$ & $580(27)$ \\
\hline & $6(\mathrm{~L})$ & $474(12)$ & $360(8)$ \\
\hline & 7 & $747(32)$ & $345(20)$ \\
\hline & $8(L)$ & $922(65)$ & $200(31)$ \\
\hline & $9(\mathrm{~S})$ & 747 (15) & $269(11)$ \\
\hline & $10(S)$ & $780(36)$ & $246(11)$ \\
\hline & 11 & $1047(22)$ & $181(5)$ \\
\hline & $12(\mathrm{~L})$ & $1096(36)$ & $210(17)$ \\
\hline & $13(\mathrm{~L})$ & $804(67)$ & $162(10)$ \\
\hline & 14 & $179(19)$ & $332(35)$ \\
\hline \multirow[t]{14}{*}{3} & 1 & $540(35)$ & 341 (16) \\
\hline & $2(\mathrm{~L})$ & $457(38)$ & $242(14)$ \\
\hline & $3(\mathrm{~L})$ & $337(27)$ & $303(21)$ \\
\hline & $4(S)$ & $528(13)$ & $215(9)$ \\
\hline & $5(\mathrm{~S})$ & $197(10)$ & $432(51)$ \\
\hline & $6(\mathrm{~L})$ & $181(7)$ & $303(10)$ \\
\hline & 7 & $283(32)$ & 248 (13) \\
\hline & $8(\mathrm{~L})$ & $366(20)$ & $172(22)$ \\
\hline & $9(\mathrm{~S})$ & 296 (17) & 189 (18) \\
\hline & $10(\mathrm{~S})$ & $263(16)$ & $202(14)$ \\
\hline & 11 & 458 (13) & 119 (10) \\
\hline & $12(\mathrm{~L})$ & $341(32)$ & $147(11)$ \\
\hline & $13(\mathrm{~L})$ & $399(33)$ & $159(4)$ \\
\hline & 14 & $102(6)$ & $140(12)$ \\
\hline \multirow[t]{14}{*}{4} & 1 & $823(43)$ & $242(9)$ \\
\hline & $2(\mathrm{~L})$ & 997 (18) & $208(8)$ \\
\hline & $3(\mathrm{~L})$ & 707 (29) & 453 (15) \\
\hline & $4(S)$ & $695(20)$ & $330(8)$ \\
\hline & $5(\mathrm{~S})$ & $361(8)$ & $481(25)$ \\
\hline & $6(\mathrm{~L})$ & $436(19)$ & $585(25)$ \\
\hline & 7 & $604(29)$ & $405(24)$ \\
\hline & $8(\mathrm{~L})$ & $875(18)$ & 278 (22) \\
\hline & $9(\mathrm{~S})$ & $612(33)$ & $430(22)$ \\
\hline & $10(\mathrm{~S})$ & $498(63)$ & $393(27)$ \\
\hline & 11 & $863(11)$ & $232(9)$ \\
\hline & $12(\mathrm{~L})$ & 800 (27) & 211 (10) \\
\hline & $13(\mathrm{~L})$ & $621(70)$ & $368(23)$ \\
\hline & 14 & 274 (19) & $212(11)$ \\
\hline
\end{tabular}

APPENDIX (Continued)

\begin{tabular}{cccc}
\hline & & \multicolumn{2}{c}{ Responses } \\
\cline { 3 - 4 } $\begin{array}{c}\text { Pi- } \\
\text { geon }\end{array}$ & Condition $^{\text {a }}$ & $\begin{array}{c}\text { Left mean } \\
(S E)\end{array}$ & $\begin{array}{c}\text { Right mean } \\
(S E)\end{array}$ \\
\hline \hline 5 & 1 & $244(13)$ & $101(8)$ \\
& $2(\mathrm{~L})$ & $331(15)$ & $120(5)$ \\
& $3(\mathrm{~L})$ & $316(15)$ & $198(26)$ \\
& $4(\mathrm{~S})$ & $424(27)$ & $161(8)$ \\
& $5(\mathrm{~S})$ & $135(13)$ & $274(13)$ \\
& $6(\mathrm{~L})$ & $151(18)$ & $175(26)$ \\
& 7 & $354(14)$ & $152(16)$ \\
& $8(\mathrm{~L})$ & $328(29)$ & $114(10)$ \\
& $9(\mathrm{~S})$ & $382(38)$ & $166(12)$ \\
& $10(\mathrm{~S})$ & $289(21)$ & $156(12)$ \\
& 11 & $277(10)$ & $142(8)$ \\
& $12(\mathrm{~L})$ & $219(17)$ & $145(6)$ \\
& $13(\mathrm{~L})$ & $195(15)$ & $142(7)$ \\
& 14 & $66(4)$ & $143(16)$ \\
\hline
\end{tabular}

${ }^{a} \mathrm{~L}$ and $\mathrm{S}$ indicate short and long conditions, respectively (see text). 